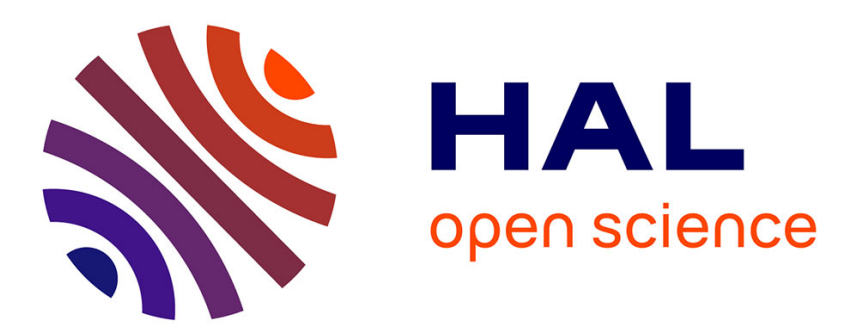

\title{
Boron doped diamond microelectrodes arrays for electrochemical detection in HPLC
}

\author{
Eric Mahé, Didier Devilliers, François Dardoize
}

\section{To cite this version:}

Eric Mahé, Didier Devilliers, François Dardoize. Boron doped diamond microelectrodes arrays for electrochemical detection in HPLC. Talanta, 2015, 132, pp.641 - 647. 10.1016/j.talanta.2014.10.028 . hal-01084129

\section{HAL Id: hal-01084129 \\ https://hal.sorbonne-universite.fr/hal-01084129}

Submitted on 18 Nov 2014

HAL is a multi-disciplinary open access archive for the deposit and dissemination of scientific research documents, whether they are published or not. The documents may come from teaching and research institutions in France or abroad, or from public or private research centers.
L'archive ouverte pluridisciplinaire HAL, est destinée au dépôt et à la diffusion de documents scientifiques de niveau recherche, publiés ou non, émanant des établissements d'enseignement et de recherche français ou étrangers, des laboratoires publics ou privés. 
Talanta Volume 132, 15 January 2015, Pages 641-647

Boron doped diamond microelectrodes arrays for electrochemical detection in HPLC

- $\quad$ Eric Mahé, Didier Devilliers, , François Dardoize

Sorbonne Universités, UPMC Univ Paris 06, CNRS, UMR 8234 PHENIX, Electrochimie et liquides ioniques,

4 Place Jussieu, 75005 Paris, France

Received 10 June 2014, Revised 30 September 2014, Accepted 2 October 2014, Available online 22

October 2014

DOI: $10.1016 / j . t a l a n t a .2014 .10 .028$

\section{Highlights}

-Boron-doped diamond microelectrodes arrays have been used as sensors for HPLC.

-These amperometric sensors have a good signal/noise ratio.

-Spacing, disposition and number of the microelectrodes have been studied, as well as influence of flow velocity.

\section{Abstract}

Boron doped diamond microelectrodes arrays (MEA) have been prepared in order to be used as new amperometric sensors in electrochemical cells for HPLC detectors. The following parameters were studied: number and diameter $(15-40 \mu \mathrm{m})$ of the electrodes, distance between them (50-240 $\mu \mathrm{m})$, and effect of the flow rate $(0.1-3 \mathrm{~mL} / \mathrm{min})$. It was thus possible to find the optimum value of the parameters which give a good signal/noise ratio in the chronoamperometric responses, with a size of the electrochemical sensors as small as possible.

\section{Graphical abstract}

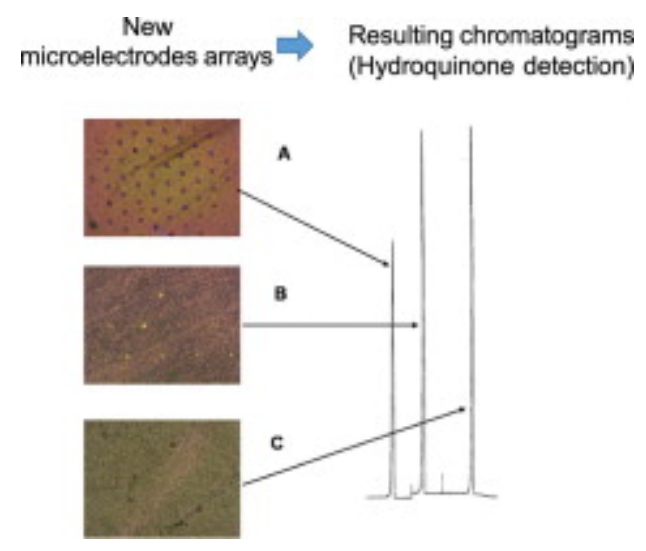




\section{Keywords}

- High performances liquid chromatography;

- Electrochemical detection;

- Boron doped diamond;

- Microelectrodes arrays (MEA)

\section{Introduction}

Electroanalysis is a powerful tool for analytical chemistry, especially considering flow analysis and amperometric HPLC detection. Forty years ago, Adams and Kissinger have started their contributions to the development of the electrochemical (EC) detection associated to liquid chromatography (LC) [1]. The principle of these detectors is based on an electron transfer reaction during the oxidation/reduction process of a target analyte, after its separation in a chromatography column, at a millimetric/centimetric solid electrode for the major part of the modern systems [2] and [3].

The use of these detectors in HPLC is attractive because of their qualities: selectivity and sensibility. Generally these detectors are not very expensive; they are composed of a simple efficient potentiostatic electronic part, associated with a high gain current follower and a sensor: a threeelectrode flow-cell, which is the sensitive part of the detector. The principle of the amperometric detectors is to apply an appropriate electric potential between the reference and the working electrode and to measure the faradaic current resulting from the analyte reaction at the working electrode. This current is proportional to the concentration of the sample after baseline correction of the residual current. Several kinds of materials were used in those cells for the working electrode considering their respective electrochemical window and stability: carbon paste, gold, platinum, silver, glassy carbon, etc. In the active volume of a cell, three mass transport mechanisms exist: convection far from the electrode surface, migration and diffusion close to the active surface of the working electrode. A number of works were done to simulate these mass transfers and provide interesting ways to improve the design of the electrochemical cells [4] and [5]. In a LC-EC flow-cell, it is assumed that the hydrodynamic regime is controlled by the competition between the convective part and the diffusional part. Péclet adimensional number is the suitable parameter for the quantification of the ratio of the convection transport rate to the diffusion transport rate.

In addition, microelectrodes [6] were widely studied for their use in analytical electrochemistry, because of the increase of the current density by the hemispherical diffusion effect, leading to a better signal/noise ratio and to a short response time [7]. However, if the current density may be high on one microelectrode, when the concentration of the sample is low the total current remains very small and 
generally arrays of microelectrodes are used to get an amplification of the current measured for signal treatments [8], [9], [10] and [11]. Theoretical studies were led to propose the best arrangement of the microelectrodes in the arrays. Usually done in static medium, they give a good idea for the distances between microelectrodes to get the different signal regimes for further studies in continuous flow [12].

In 1987, it was shown by Pleskov et al. [13] that synthetic diamond doped with boron (BDD) becomes conductive and offers a high overpotential for oxygen or hydrogen evolution. There is an important focus on the development of this material which could be attributed to its numerous qualities: chemical inertness, mechanical durability, low background current and wide electroactive window. For that reason, it has been proposed as an anodic material for the oxidation of organic pollutants [14]. In addition, it is easy to clean in situ [15].

The research of the lowest concentration detection is a constant goal in HPLC. This goal can be reached by combining the qualities of the diamond material and the array of microelectrodes in an amperometric detector. The parameters which must be taken into account to manufacture optimized BDD microelectrodes array (MEA) for HPLC amperometric detection are studied in the present work.

To our knowledge, the first operational application of microelectrodes for the use in HPLC was done by Kissinger and colleagues [16]. An interdigitated array of microelectrodes was used to enhance the current obtained in a redox cycling process in a flow stream at the output of an HPLC column. The results show a higher current density and lower noise due to the size effect of the microelectrodes array used, compared to a macro-electrode with the same geometric area.

The interest of microelectrodes has met a fast development, the microdisc electrodes were widely used to study rapid electron transfer processes and theoretical models were proposed for the mass transport on different shapes of microelectrodes in static cells [17] and [18].

More and more techniques were employed to machine arrays of microelectrodes, for example, sealed wires in epoxy with a polishing of the surface [19], easy to produce but with a poor reproducibility; arrays have been constructed on silicon substrates using electron beam lithography [20], or multilayer systems with conductive carbon ink laid on a polymer surface and covered by an insulator film. The electrodes are obtained by laser drilling, leading to small holes through the insulator down to the carbon ink [21]. This process offers numerous possibilities to modify the diameter of the electrodes, their number and their spacing. It allows the manufacturing of different arrays and so, verifying if the tests are in agreement with the theory.

The first use of these arrays is for cyclic voltammetry with the electrodes in a static cell with fast-scan technique [17]. However, Aixill et al. [22] demonstrated the good agreement between the theory to predict the current at a micro-strip electrode taking into account the lateral diffusion, normal diffusion and axial convection and the experimental results obtained with a home-made cell with platinum strips 
as working electrodes and the oxidation of tris(4-bromophenyl)amine in continuous flow-cells. The results show an enhanced mass transport characteristic compared with equivalent macro-electrodes. In practical devices, the machining of the micro-arrays introduces a finite thickness of the insulating layer or a recessed geometry of the conductive part, responsible of the local perturbation of the flow. A simulation of the effect was realized [23] for the two cases with the strips across the flow and for different linear speeds of the liquid. For recessed micro-band electrodes, the formation of eddies inside the cavities led to an increase of a stagnant flow at the bottom which prevents the renewal of the electro-active species. The industry of semiconductors has introduced new technologies to produce thin insulating films with hard materials; the applications of these techniques allowed the production of arrays of microelectrodes with the recess depth of $500 \mathrm{~nm}$ [24]. In reference with a previous work of Heinze [25] for recessed single microdisc electrodes, a new equation has been proposed [24] for the steady state current:

equation(1)

$L_{\text {thon }}=\pi a^{2} n F D \frac{C}{a+n}$

where $a$ is the radius of the microdisc; $n$, the number of electrons exchanged; $F$, the Faraday constant; $D$, the diffusion coefficient; $h$, the height of the recess and $C$ the concentration of the electroactive species.

If the electrode may be considered as a single inlaid microdisc, equation can be used as follows:

equation(2)

$\mathrm{I}_{\mathrm{Iim}}=4$ a n F D C llim=4anFDC

Several arrays were made with different radii, from $2.5 \mu \mathrm{m}$ up to $100 \mu \mathrm{m}$ and distances between the electrodes from $30 \mu \mathrm{m}$ to $750 \mu \mathrm{m}$. In static mode and cyclic voltammetry, larger electrodes produced a current more important than predicted by Eq. (1) because that equation is only valid for microelectrodes. As expected, the current obtained from calculations and from experiments is similar when the distance/radius ratio is large [24].

The chemical vapor deposition (CVD) of diamond and the possibility to introduce a p-type dopant during the growing process of diamond provide a material which becomes conductive with the physical properties of diamond. It was very attractive to use this material in electroanalysis. Several hundreds of reviews [26], [27] and [28] were published on applications of these electrodes in cyclic voltammetry for the analysis of pesticides, herbicides, pharmaceutical products [29], [30] and [31]. The conductive diamond was also used to manufacture electrodes for electrochemical detection in HPLC and flow injection [32], [33], [34], [35], [36], [37] and [38] electrochemical reactions [39].

The applications were extended to arrays of microelectrodes [39], [40] and [41]. The techniques employed for manufacturing the diamond arrays of electrodes where more or less sophisticated, from photolithography up to pattern the isolation surface with a powerful laser beam [42]. Multi-layers arrays 
were obtained by the deposition of conductive and non-conductive diamond on a solid substrate. $0.6 \mu \mathrm{m}$ electrodes were obtained by etching with an oxygen/argon plasma process [43].

It was interesting to investigate the possibility to combine the properties of the BDD with the principle of microelectrodes as fabricated by Fujishima and colleagues [36] and [40] to manufacture new sensors for HPLC.

In this paper, the parameters which drive the responses of the detector were studied to provide a cell for electrochemical detection in HPLC.

\section{Experimental}

With HPLC, the sensor works in continuous flow, to avoid a mixture of the products separated in the column. The volume of the cell must be as small as possible (less than $5 \mu \mathrm{L}$ ); the classical flow rate was set at $1 \mathrm{~mL} / \mathrm{min}$, which roughly led to a velocity of the flow of $1-1.5 \mathrm{~m} / \mathrm{min}$ in the cell considering the cell geometry.

\subsection{Chemicals}

The electrochemical tests were mainly realized using hydroquinone as a model analyte related to interesting molecules separated through HPLC.

Quinone/hydroquinone redox functional group is encountered in many natural or synthetic biological, pharmaceutical and environmental important analytes (catecholamine neurotransmitters, ubiquinone coenzymes, emodine pharmaceutical agent, chloranil analog pesticides, etc.). The solutions were prepared with the eluent for chromatography: $8 \% \mathrm{CH}_{3} \mathrm{CN}$ in a $10^{-3} \mathrm{M}$ solution of $\mathrm{LiClO}_{4}$ (Sigma-Aldrich, France). The solutions were prepared every day and kept in an ice bath. The water (resistivity: $18 \mathrm{M} \Omega \mathrm{cm}$ ) was obtained from a Milli-Q apparatus (Millipore, France).

\subsection{Apparatus}

Electrochemical experiments were performed with an Eldec 105 (Precision Instruments, Marseille, France) amperometric detection unit. The three-electrode cell of the detector is shown in Fig. 1. It has been adapted to receive the BDD electrodes array as working electrode, an $\mathrm{Ag} / \mathrm{AgCl}$ reference electrode and a stainless steel counter electrode. The inlet and outlet of the flow and a hole for inserting the reference electrode are located at the upper part of the cell. The inlet and outlet diameters are: $0.4 \mathrm{~mm}$ and the channel height is about $50 \mu \mathrm{m}$. The potential of the working electrodes was $0.7 \mathrm{~V}$ vs Ref for all the experiments in order to investigate hydroquinone functional group oxidation process (the standard potential of the quinone/hydroquinone redox couple is about $0.5 \mathrm{~V}$ vs $\mathrm{Ag} / \mathrm{AgCl}$ ). The chromatography experiments were carried out using a Dionex pump (Montigny le 
Bretonneux, France), an injection valve Negretti and Zambra (UK), a $15 \mathrm{~cm}$ column, $4.6 \mathrm{~mm}$ inside diameter, C $18.5 \mu \mathrm{m}$ Waters Symmetry. The chromatograms were directly recorded on a Kipp and Zonen BD 111 recorder or a Shimadzu CR 6 A integrator.

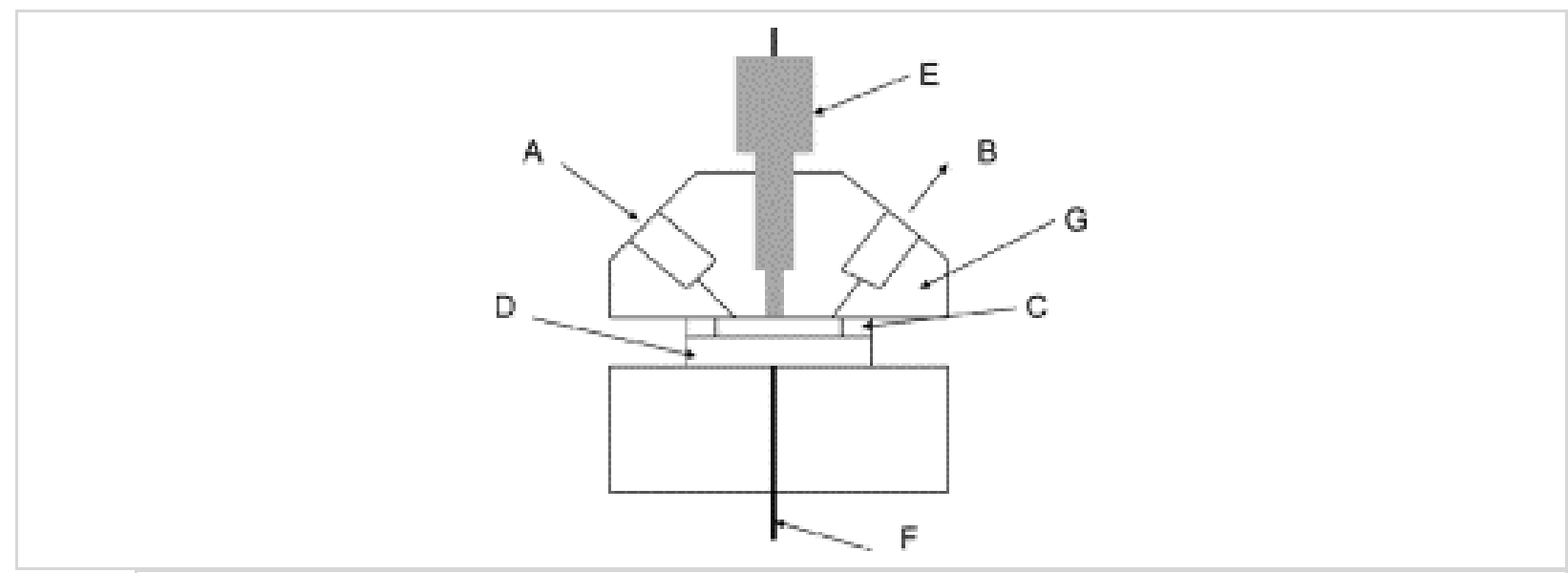

Fig. 1.

Electrochemical flow-cell fitted with a BDD microelectrodes array as the working electrode: A: inlet, B: outlet, C: seal, D: diamond microelectrodes array, E: reference electrode, F: contact for working electrode, G: auxiliary electrode.

\subsection{Arrays of electrodes}

Several arrays of microelectrodes were manufactured in accordance with our drawings by the Commissariat à l'Energie Atomique (CEA, Saclay, France) to investigate the problems which arise with the use of the microelectrodes in a continuous flow. The manufacturing procedure was described elsewhere [44], and may be summarized rapidly: on a p-Si boron-doped substrate, a conductive boron-doped diamond film was grown using microwave plasma chemical vapor deposition. Then, nonconductive diamond was deposited to cover the first film to produce an insulator. Finally, this last layer was patterned with a laser beam to obtain the arrays of microelectrodes through the insulator down to the conductive diamond. The sensor $\left(15 \times 15 \mathrm{~mm}^{2}\right.$ geometrical area, $1.5 \mathrm{~mm}$ thick) was placed in the cell described in Fig. 1. A seal is used to insure the water-tightness between the upper block of the cell and the array, a Kel-F block with a hole to get the contact with the array. A film of indium/gallium alloy was laid on the back of the silicon substrate under the array in order to have an ohmic electric contact. The two parts of the cell were screwed together to compress the seal.

\section{Results}

\subsection{Tests with one microelectrode}


A single microelectrode with a diameter of $17 \mu \mathrm{m}$ was prepared and examined by Scanning Electron Microscopy (see Fig. 2) in order to check the quality of the preparation procedure. From SEM experiments, it was shown that the thickness of the diamond insulator was about $300 \mathrm{~nm}$.

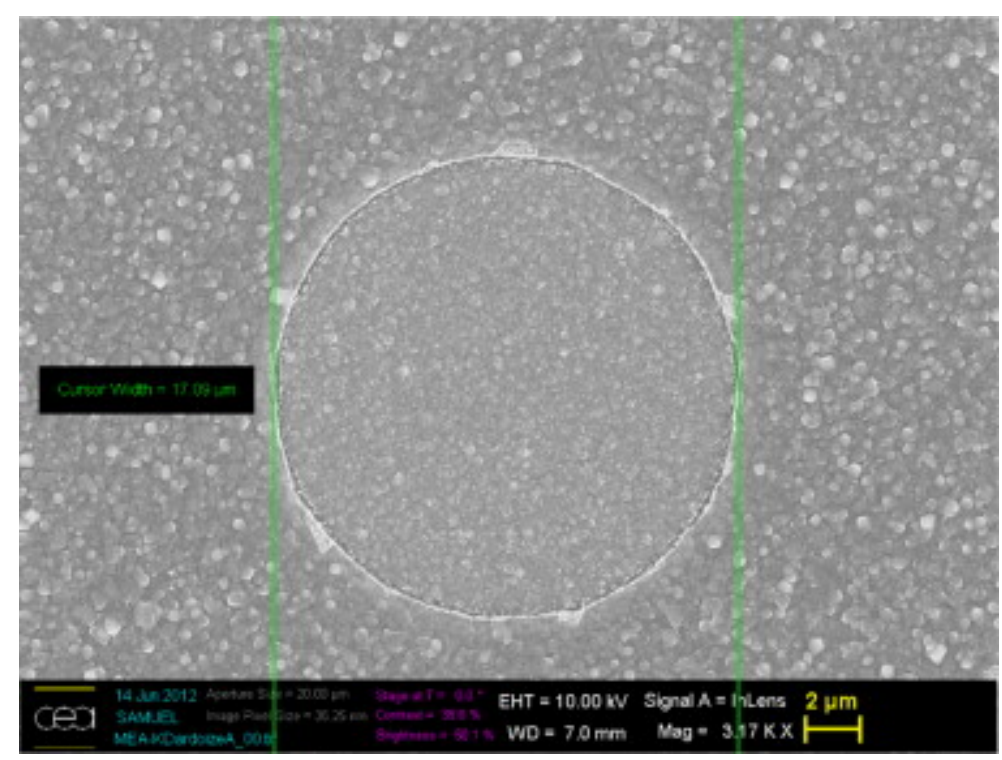

Fig. 2.

Electron microscope picture of one microelectrode. Diameter of the BDD electrode: $17 \mu \mathrm{m}$, thickness of the insulator: $300 \mathrm{~nm}$.

The $17 \mu \mathrm{m}$ microelectrode was inserted in the cell of the electrochemical detector and a chromatography test was realized by the injection of $20 \mu \mathrm{L}$ of a solution which contains $18 \mu \mathrm{g}$ of hydroquinone. A peak of $0.8 \mathrm{nA}$ was obtained with a retention time of $5 \mathrm{~min}$ with our conditions, a good signal/noise ratio and a fast equilibration time of the electrode, less than observed on millimetric BDD electrodes.

Another single disc microelectrode with a diameter of $40 \mu \mathrm{m}$ was prepared for studying its voltammetric response. A 3-dimension AFM picture and a schematic profile of that electrode are given in Fig. 3A. As the ratio $h / a$ is very small (about 0.01), Eq. (2) may be used, instead of Eq. (1). The radius, $a$, of the inlaid microdisc electrode may be calculated from the measurement of steady state limiting current llim. The cyclic voltammogram shown in Fig. 3B was performed with ferrocenemethanol $1 \mathrm{mM}$ in phosphate buffer saline solution with a scan rate of $5 \mathrm{mV} \mathrm{s}^{-1}$. From Eq. (2), one can calculate the experimental radius $a \approx 20 \mu \mathrm{m}$, in agreement with the AFM image ( Fig. 3A). It can be established from that behavior that the insulating diamond layer has no pinholes defects. 
A

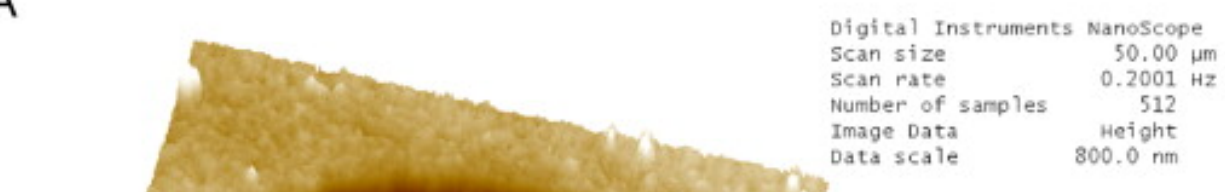

$\times 10.000 \mu \mathrm{m} / \mathrm{div}$

$2800.000 \mathrm{~nm} / \mathrm{div}$

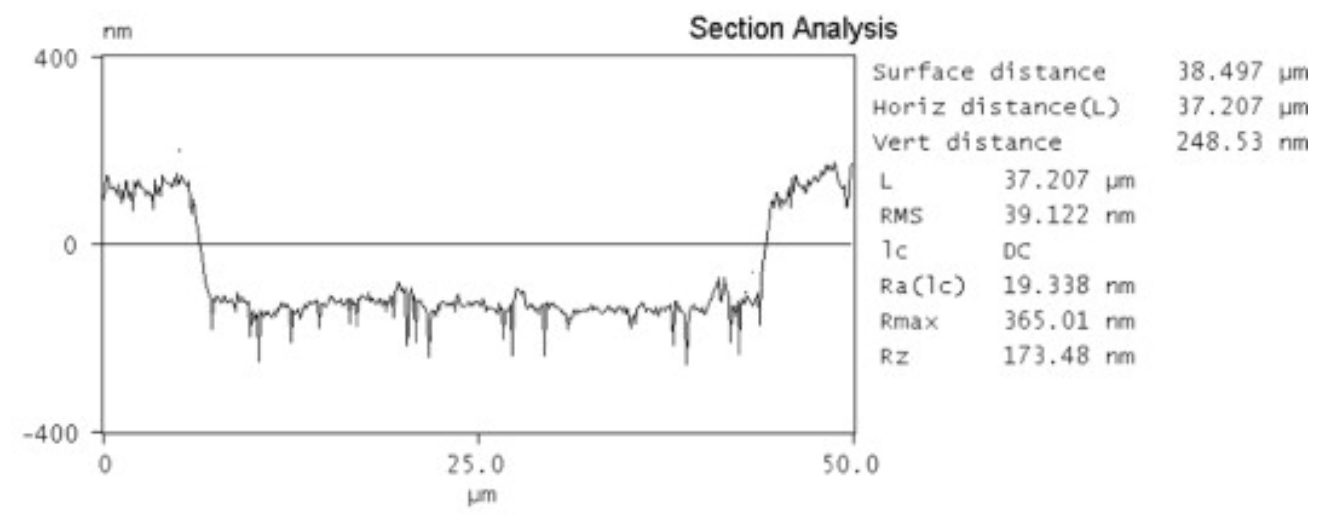

B

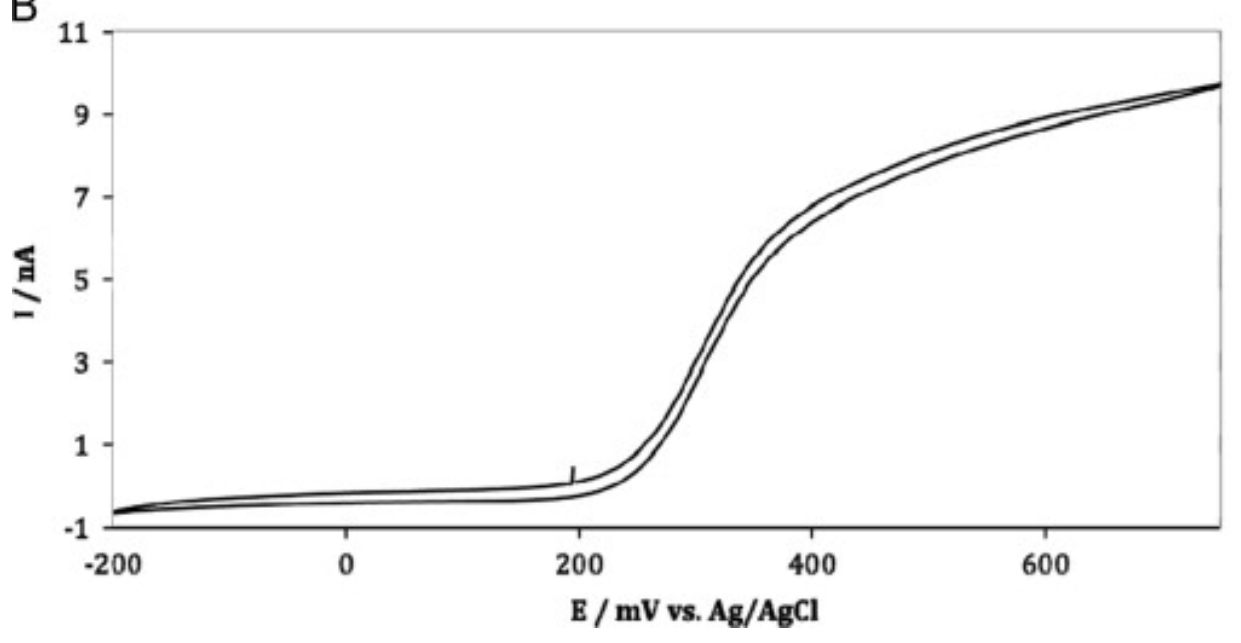

Fig. 3. Study of a single $40 \mu \mathrm{m}$ BDD microelectrode (A): AFM picture and schematic profile of the recess of the electrode. (B): cyclic voltammetric response. Ferrocenemethanol $1 \mathrm{mM}$ in phosphate buffer saline solution with a scan rate of $5 \mathrm{mV} \mathrm{s}^{-1}$. 


\subsection{Tests with arrays of microelectrodes}

A simple idea was to increase the number of electrodes in order to inject lower quantities of product and increase the signal.

Several arrays were manufactured, suitable for the geometry of the electrochemical cell. As can be seen from Fig. 4, very regular hexagonal arrangements of electrodes could be obtained. On the center of a multi-layer piece as described previously, an array was machined: about 16,000 electrodes with a diameter $\phi=2 a=15 \mu \mathrm{m}$, with a distance $d=45 \mu \mathrm{m}$ between the electrodes $(d / a=6)$, were arranged in a circle with a diameter of $6 \mathrm{~mm}$. This regular arrangement gave an active surface of around $2.8 \mathrm{~mm}^{2}$. After an equilibration time of $12 \mathrm{~min}$, a sensitivity of $0.1 \mathrm{nA} / \mathrm{FS}$ (Full Scale) was reached on the detector with a flat base line; the injection of $90 \mathrm{pg}$ of hydroquinone in $20 \mu \mathrm{L}$ (corresponding to a concentration of $4 \times 10^{-8} \mathrm{~mol} \mathrm{~L}^{-1}$ ) gave a peak of $0.03 \mathrm{nA}$ with a signal/noise ratio of $30 / 1$ ( Fig. 5).

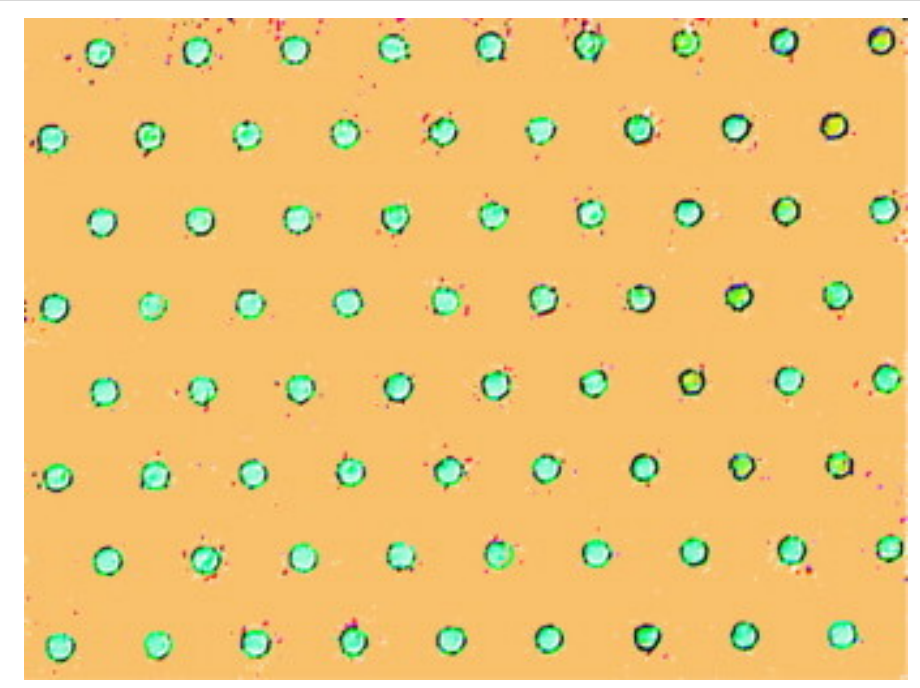

Fig. 4.

Array of microelectrodes. The diameter of each microelectrode is $15 \mu \mathrm{m}$ with a distance of $60 \mu \mathrm{m}$ between the electrodes. Size of the picture: $542 \mu \mathrm{m} \times 407 \mu \mathrm{m}$. 


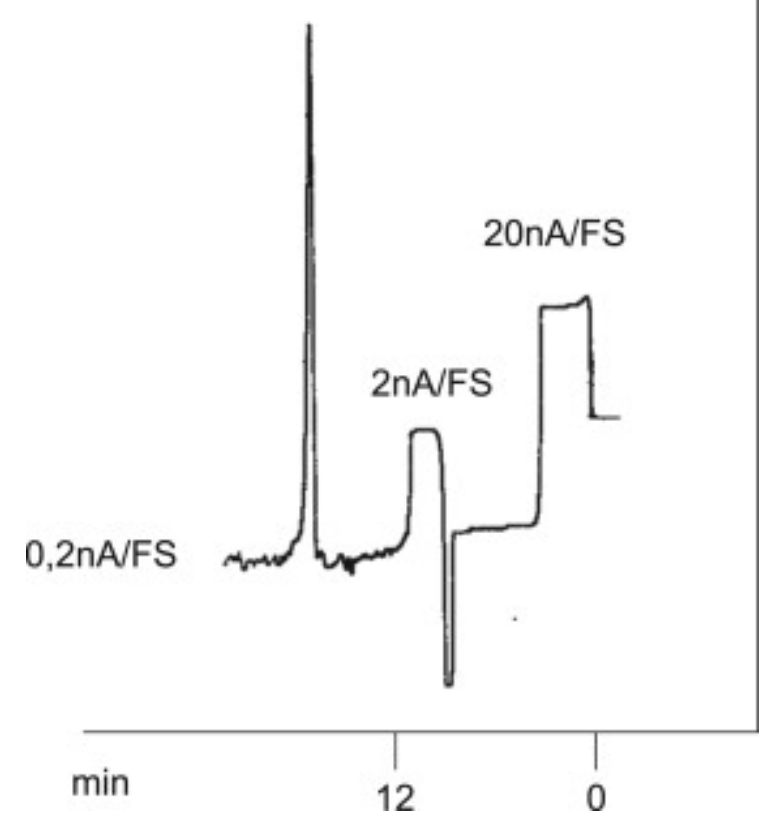

Fig. 5.

Chromatogram of the injection of $90 \mathrm{pg}$ of hydroquinone. Quick equilibration time of the cell: 12 min to reach the sensitivity of $0.1 \mathrm{nA} / \mathrm{FS}$. Signal of $0.03 \mathrm{nA}$ with a ratio $S / N=30 / 1$.

\subsection{Study of the arrays geometry}

In order to enhance the sensibility of electrode arrays and get the best signal/noise ratio, several parameters have to be studied: number of electrodes, diameter of the electrodes, distance between the electrodes and effect of the flow rate.

\subsubsection{Distance between the electrodes}

In our cell, a flow rate value of $1 \mathrm{~mL} / \mathrm{min}$ was chosen, corresponding to a velocity of the flow inside of the cell around $1.5 \mathrm{~m} / \mathrm{min}$, taking into account its volume $(4.5 \mu \mathrm{L})$, whilst most of the works on microelectrodes array found in the literature were done without flow. It was necessary to determine the distance between the electrodes which produces the highest signal and exhibits the benefit of microelectrodes. Three arrays were manufactured with 68 disc microelectrodes with a diameter of $15 \mu \mathrm{m}$ and a depth of $300 \mathrm{~nm}$. The distance between two consecutive electrodes in the flow was 50, 120 or $240 \mu \mathrm{m}$, in a hexagonal geometry ( $d a=6.7,16$ or 32 , respectively). The arrays were successively placed in the cell of the electrochemical detector. After equilibration at a flow rate of $1 \mathrm{~mL} / \mathrm{min}$, a solution of $80 \mathrm{ng}$ of hydroquinone in $20 \mu \mathrm{L}$ was injected (concentration: $3.5 \times 10^{-5} \mathrm{~mol} \mathrm{~L}^{-1}$ ). The arrays with a distance between the electrodes of 120 and $240 \mu \mathrm{m}$ provide a signal of $0.9 \mathrm{nA}$, while 
the array with a distance of $50 \mu \mathrm{m}$ gives a signal of only $0.64 \mathrm{nA}$ ( Fig. 6). One can conclude that, for the chosen diameter $\phi=15 \mu \mathrm{m}$, the value $d l a=6.7$ is not sufficient for optimizing the signal-to-noise ratio for the same number of microelectrodes.

\section{A}

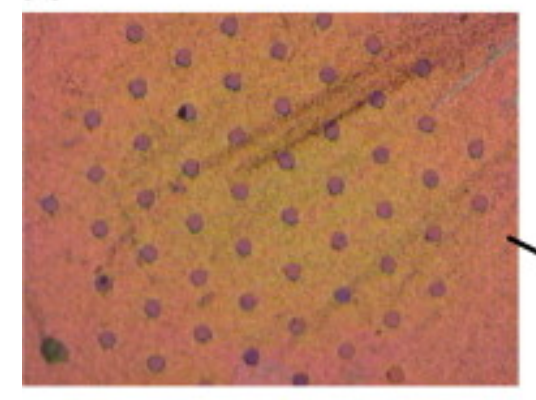

B
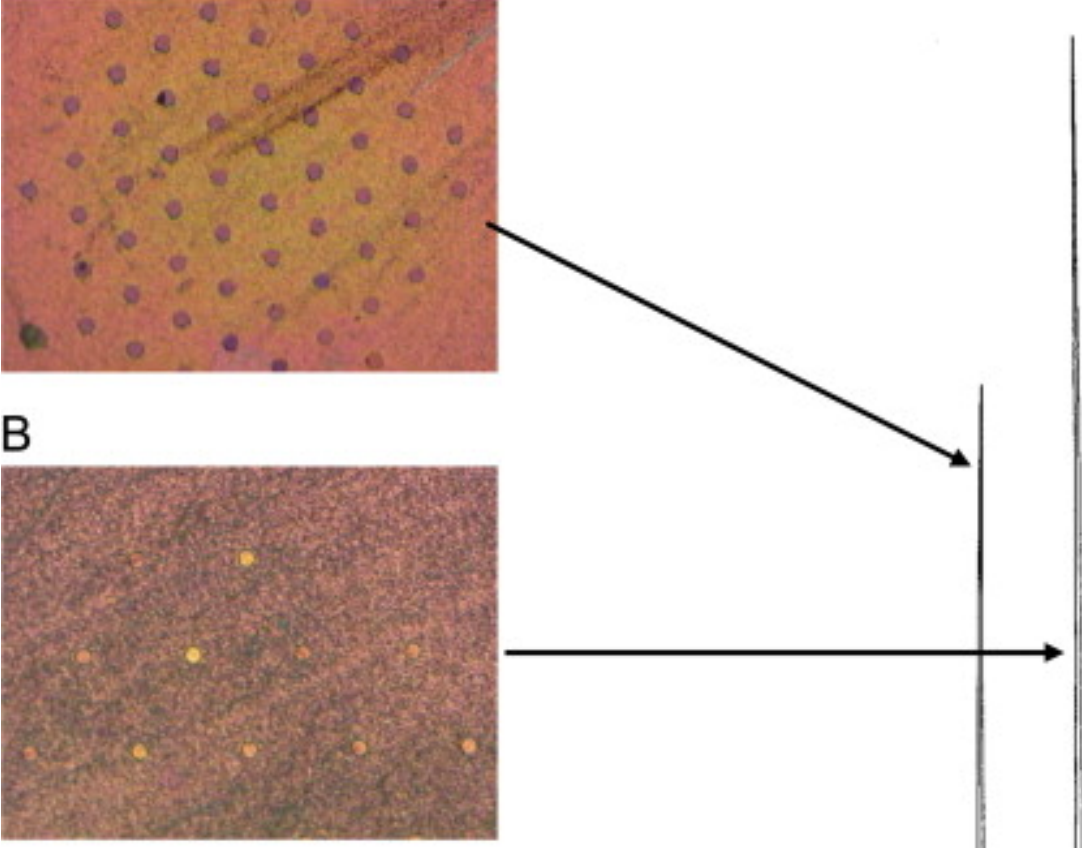

C

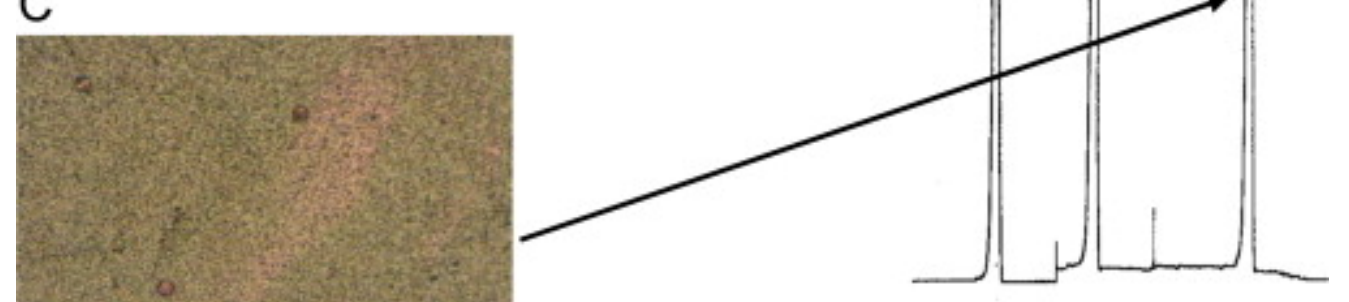

Fig. 6 .

Chromatograms obtained by the injection of $80 \mathrm{ng}$ of hydroquinone on three different arrays with 68 electrodes of $15 \mu \mathrm{m}$ of diameter on each array. The electrode spacing was: 50 (A), 120 (B) or 240 (C) $\mu \mathrm{m}$. A signal of $0.64 \mathrm{nA}$ was recorded for the array A. With the arrays $B$ and $C$ the same signal of $0.9 \mathrm{nA}$ was recorded.

Taking into account the velocity of the flow inside the cell, we think that, due to the depletion, the hydroquinone molecules, oxidized at the electrode, are not completely renewed by forced convection if the electrodes are too close. Hereafter, a ratio $d l a=16$ has been chosen for the subsequent experiments.

\subsubsection{Effects of the flow rate}


The study of the chronoamperometric response of a recessed micro-band electrode was done by other authors by simulation [23]. In this case, it was clearly demonstrated that there is a relation between the chronaoamperometric response of the electrode and the velocity of the flow via the Péclet number. The Péclet number can be calculated from the average flow velocity, $u$, the channel height, $h$, and the diffusion coefficient $D$ :

equation(3)

$\mathrm{Pe}=\mathrm{uh} / \mathrm{D}$

In our experiments, $P e$ is in the range $250-5000$.

Several arrays were prepared to determine the arrangement of electrodes which provides the best signal/noise ratio in chromatographic conditions with different flow rates.

The electron transfer occurring at the electrode is a function of several parameters. Several tests, reported in Fig. 7, were done using an array of 68 electrodes ( $\phi=15 \mu \mathrm{m}, d=120 \mu \mathrm{m}$, and $d / a=16)$ increasing the flow rate from $0.1 \mathrm{~mL} / \mathrm{min}$ up to $3 \mathrm{~mL} / \mathrm{min}$. The same samples were injected: $70 \mathrm{ng}$ of hydroquinone in $20 \mu \mathrm{L}$ (concentration: $3 \times 10^{-5} \mathrm{~mol} \mathrm{~L}^{-1}$ ). A decrease of the normalized peak area was observed (black full circles in Fig. 7). It can be attributed to the change of the residence time of the analyte in front of each microelectrode with the variation of the flow rate. For flow rates that have been tested in this work, in the magnitude order of $1 \mathrm{~mL} / \mathrm{min}$, the characteristic residence time, $T r$, of analyte flux over each microelectrode surface is shorter than the diffusion time, $T d$, at each microelectrode. The $T H T d$ ratio can be understood as an efficiency parameter linked to the amount of analyte detected at the microelectrodes array sensor. $T r$ is controlled by the flux rate in the cell and by the thickness of the flow cell, whereas $T d$ is controlled by the geometry of the electrodes.

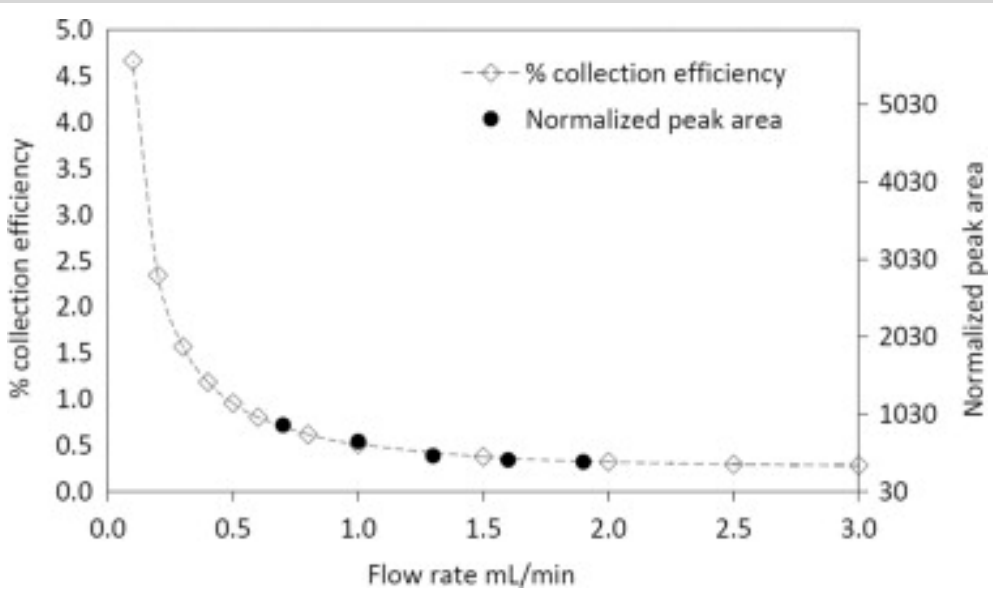

Fig. 7.

Correlated variations of the area of the peak and the collection efficiency of the flow-cell versus the flow rate. An array of 68 electrodes was used, with a distance between the electrodes of $120 \mu \mathrm{m}$. 
We have calculated the collection efficiency of the microelectrodes array with a standard injection volume of $20 \mu \mathrm{L}$ of analyte from the experimental measurement of the electric charge consumed for the detected peak. The collection efficiency of the flow-cell detector can be defined as the ratio of the experimental charge to the calculated charge needed to oxidize the whole amount of injected analyte. When the flux rate increases the collection efficiency diminishes (Fig. 7). It means that the amount of analytes reacting at the electrodes diminishes drastically due to the decrease of the residence time of species close to each microelectrode.

From those experiments, it should be noticed that the critical parameter for an HPLC amperometric detector is not the collection efficiency alone, but also the highest possible signal-to-noise ratio compatible with on-line detection at the outlet of the HPLC column.

\subsubsection{Diameter and number of the electrodes}

An important parameter in the detector for HPLC is the void volume of the sensor, the smallest as possible not to lose the quality of the separation by dilution inside the cell. The simplest solution for amplifying the signal is to increase the number of electrodes or/and to increase the size of the electrodes. Taking into account the previous results, an array was manufactured for reaching a good compromise: the electrodes, with $\phi=30 \mu \mathrm{m}$ are placed in staggered rows, at a distance of $100 \mu \mathrm{m}$ between the electrodes $(d / a=6.7)$. The 5800 electrodes are gathered in a circle with a diameter of $8 \mathrm{~mm}$, the active area is around $4.1 \mathrm{~mm}^{2}$ and the internal volume of the cell is close to $4.5 \mu \mathrm{L}$. A typical result is displayed in Fig. 8. After 12 min equilibration time, the detector is set at $0.1 \mathrm{nA} / \mathrm{FS}$, the injection of $16 \mathrm{pg}$ of hydroquinone gave a peak of $0.07 \mathrm{nA}$ with a high signal/noise ratio 55/1. Indeed, the $d l a$ parameter in not the only pertinent criterion. The diameter of the microdisc electrode must also be taken into account for the optimization of the detector. 


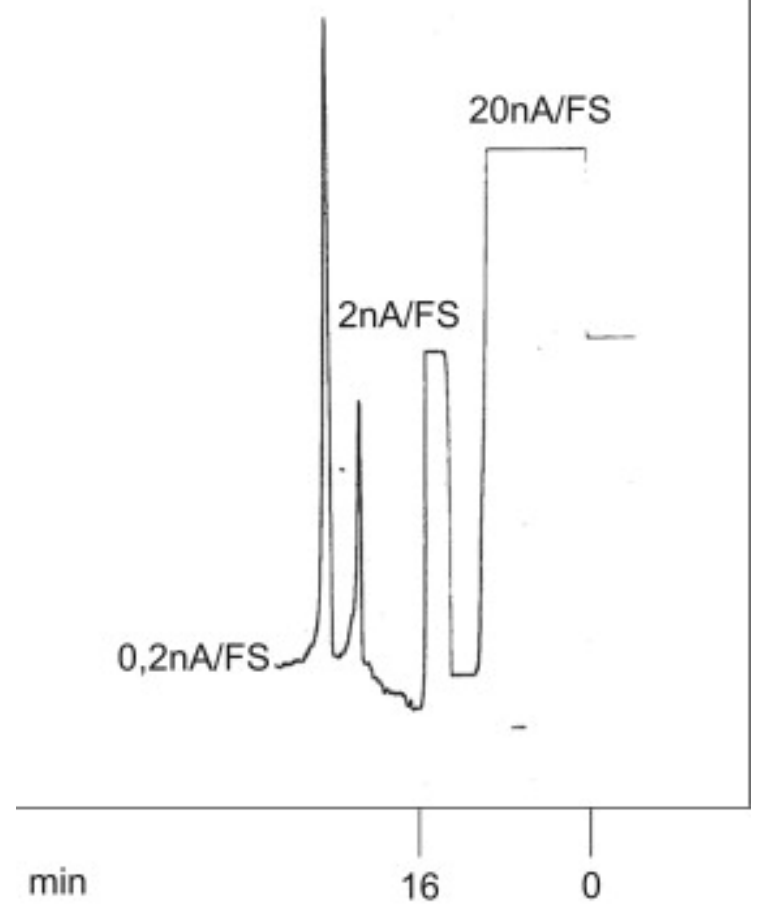

Fig. 8.

Chromatogram obtained with the selected array: diameter of the electrodes: $30 \mu \mathrm{m}$, distance between the electrodes: $100 \mu \mathrm{m}$, active surface area: $4.1 \mathrm{~mm}^{2}$. Injection of $16 \mathrm{pg}$ of hydroquinone. After equilibration, the change of the sensitivity set on the detector was directly noted on the chromatogram, a peak of $0.07 \mathrm{nA}$ was obtained with a ratio $S / N=55: 1$.

\section{Conclusion}

Boron-doped diamond has been used as a highly efficient electrode material for electrochemical detectors in high flow rate conditions. It offers a wide range of electro-activity, a quick equilibration time and an easy in situ cleaning. By combining its remarkable qualities with the particular properties of arrays of microelectrodes, new sensors for the electrochemical detection in HPLC were designed. Several series of arrays were prepared to determine the effect of the size of the electrodes, their spacing, disposition and number. Taking into account these results, a sensor was manufactured to be inserted in the cell of an electrochemical detector, leading to the detection of very small amounts of hydroquinone at the picogram scale, after a short equilibration time, less than $15 \mathrm{~min}$, and a high signal/noise ratio.

Three key parameters have been identified for the optimization of the detection: the flux velocity, which controls the collection efficiency; the dla ratio, which controls the signal to noise ratio and, at last, the 
diameter of the microdiscs, which is related to the sensitivity. A more extensive study should lead to the optimal electrochemical detector for HPLC.

\section{Acknowledgements}

The authors wish to thank Dr P. Bergonzo and his group of the LIST, CEA (Saclay, France) for the manufacturing of the arrays and the fruitful discussions which have allowed the development of this work. Precision Instruments (Marseille, France) is also acknowledged for financial support and industrial development of the cells fitted with BDD arrays for electrochemical detection in HPLC.

\section{References}

[1] P.T. Kissinger, C. Refshauge, R. Dreiling, R.N. Adams, Electrochemical detector with picogram sensitivity, Anal. Lett. 6 (1973) 465-477.

[2] M. Goto, T. Nakamura, D. Ishii, Micro high performances liquid chromatography with micro precolumn and dual electrochemical detector for direct injection analysis of catecholamines in body fluids, J. Chromatogr. 226 (1981) 33-42.

[3] D.A. Roston, P.T. Kissinger, Identification of phenolic constituents in commercial beverages by liquid chromatography with electrochemical detection, Anal. Chem. 53 (1981) 1695-1699.

[4] I. Streeter, R.G. Compton, Measuring the size distribution of microelectrodes in an array, Sensors and Actuators B 130 (2008) 620-624.

[5] D. Barak-Shinar, M. Rosenfeld, S. Abboud, Numerical simulation of mass transfer processes in 3D model of electrochemical sensors, J. Electrochem. Soc. 151 (2004) H261H266.

[6] K. Stulik, C. Amatore, K. Holub, V. Marecek, W. Kutner, Microelectrodes. Definitions, characterization and applications, Pure Appl. Chem. 72 (2000) 1483-1492.

[7] S. Fletcher, M.D. Horne, Random assemblies of micro electrodes (RAM electrodes) for electrochemical studies, Electrochem. Commun. 1 (1999) 502-512.

[8] C. Amatore, in Physical Electrochemistry: Principles, Methods and Applications, Rubinstein I. (Ed.), Marcel Dekker, New York, 1995, Chap. 4, pp. 131-208.

[9] K. Stulik, V. Pacakova, Electroanalytical Mesurements in Flowing Liquids, E. Horwood, Chichester, 1987.

[10] C. Belmont-Hebert, M.L. Tercier, J. Buffle , G.C. Fiaccabrino, N.F. De Rooij, M.

Koudelka-Hep, Gel integrated microelectrodes arrays for direct voltametric measurements of heavy metals in natural waters and other complex media, Anal. Chem.70 (1998) 2949-2956. [11] R. Feeney, S.P. Kounaves, On site analysis of arsenic in ground water using a micro fabricated gold micro electrode, Anal. Chem. 72 (2000) 2222-2228.

[12] H.J. Lee, C. Beriet, R. Ferrigno, H.H. Girault, Cyclic voltammetry at regular microdisc electrode array, J.Electroanal.Chem.502 (2001) 138-145.

[13] Y.V. Pleskov, A.Y. Sakharova, M.D. Krotova, L.L. Bouilov, B.V.Spitsyn, Photo electrochemical properties of semiconductor diamond, J. Electroanal. Chem. 228 (1987) 1927. 
[14] D. Gandini, E. Mahé, P.A. Michaud, W. Haenni, A. Perret, Ch. Comninellis, Oxidation of carboxylic acids at boron-doped diamond electrodes for wastewater treatment, J. Applied Electrochem. 30 (2000) 1345-1350.

[15] E. Mahé, D. Devilliers, Ch. Comninellis, Electrochemical reactivity at graphitic microdomains on polycrystalline boron doped diamond thin-films electrodes, Electrochim. Acta 50 (2005) 2263-2277.

[16] O. Niwa, H.Tabei, B.P Solomon, F. Xie, P.T. Kissinger, Improved detection limit of catecholamines using liquid chromatography electrochemistry with an interdigitated array micro electrodes, J.Chromatogr. B 670 (1995) 21-28.

[17] C. Amatore, C.J. Lefrou, New concept for a potentiostat for on line ohmic drop compensation in cyclic voltametry above 300 kV/s, J. Electroanal.Chem. 324 (1994) 33-58. [18] A.M. Bond, P.J. Mahon, K.B. Oldham, C.G. Zoski, Investigation of influence of residual uncompensated resitance and incomplete changing current correction on the calculation of electrodes kinetic when global and convolution methods are used, J. Electroanal. Chem. 366 (1994) 15-27.

[19] T.W. Sohn, P.W. Stoecker, W. Carp, A.M. Yacynych, Microarray electrodes as biosensors, Electroanal. 3 (1991) 763-766.

[20] T. Hepel, J. Osteryoung, Electrochemical characterization of electrodes with sub micrometer dimensions, J. Electrochem. Soc.133 (1986) 752-757.

[21] B.J. Seddon, Y. Shao, H.H. Girault, Printed micro electrodes array of amperometric sensor for enviromental monitoring, Electrochim. Acta 39 (1994) 2377-2386.

[22] W.J. Aixill, A.C. Fischer, Q. Fulian, Hydrodynamic microelectrodes.The Microstrips Electrode: Theory and Experiment, J. Phys. Chem.100 (1996) 14067-14073.

[23] R. Ferrigno, P.F. Brevet, H.H. Girault, Finite element simulation of the amperometric response of recessed and protruding electrodes in flow channel, J. Electroanal. Chem. 430 (1977) 235-242.

[24] M.E. Sandison, N. Anicet, A. Glidle, J.M. Cooper, Optimization of the geometry and porosity of microelectrodes arrays for sensor design, Anal. Chem. 74 (2002) 5717-5725.

[25] J. Heinze, Ultramicroelectrodes in electrochemistry, Angew. Chem. 32 (1993) 12681288.

[26] K. Peckova, J. Musilova, J. Barek, Boron-doped diamond film electrodes .New tool for voltametric determination of organic substances, Crit. Rev. Anal. Chem. 39 (2009) 148-172. [27] Y. Zhou, J. Zhi, The application of boron-doped diamond electrodes in amperometric biosensors, Talanta 79 (2009) 1189-1196.

[28] J.H.T. Luong, K.B. Male, J.D. Glennon, Boron-doped diamond electrode: synthesis, characterization, functionalization and analytical applications, Analyst 134 (2009) 1965-1979.

[29] L. Svorc, M. Rievaj, D. Bustin, Green electrochemical sensors for environmental monitoring of pesticides. Determination of atrazine in river water using a boron-doped diamond electrode, Sensors and Actuators B 181 (2013) 294-300.

[30] L. Bandzuchova, L. Svorc, J. Sochr, J. Svitkova, J. Chyrlkova, Voltametric methods for sensitive determination of herbicide picloram in environmental and biological samples using boron-doped diamond film electrodes, Electrochim. Acta 111 (2013) 242-249.

[31] B.C. Lourencao, R.A. Medeiros, R.C. Rocha-Filho, L.H. Mazo, O. Fatibello-Filho, Simultaneous voltametric determination of paracetamol and caffeine in pharmaceutical formulation using boron-doped diamond electrodes, Talanta 78 (2009) 748-752. 
[32] I. Martins, F.C. Carreira, L.S. Canaes, I.A. de Souza Campos (Jr), L.M. da Silva Cruz, S. Rath, Determination of parabens in shampoo using high performance liquid chromatography with amperometric detection on a boron- doped diamond electrode, Talanta 85 (2011) 1-7. [33] Z. Bartosova, D. Jirovsky, A. Horna, High performance liquid chromatography method with amperometric detection employing boron-doped diamond electrode for the determination of sildenafil, vardenafil and their main metabolites in plasma, J.Chromatogr. A 1218 (2011) 7996-8001.

[34] W. Siangproh, P. Rattanarat, O. Chailapakul, Reverse phase liquid chromatographic determination of $\alpha$-lipoic acid in dietary supplements using a boron-doped diamond electrode, J. Chromatogr.A 1217 (2010) 7699-7705.

[35] R.A. Medeiros, B.C. Lourencao, R.C. Rocha-Filho, O. Fatibello-Filho, Flow injection simultaneous determination of synthetic colorants in food using multiple pulses amperometric detection with a boron-doped diamond electrode, Talanta 99 (2012) 883-889.

[36] T.A. Ivandini, B.V. Sarada, C. Terashima, T.N. Rao, D.A.Tryk, H. Ishiguro,Y. Kubota, A. Fujishima, Gradient liquid chromatography of leucine - encephalin peptide and its metabolites with electrochemical detection using highly boron-doped diamond electrode, J. Chromatogr. B 791 (2003) 63-72.

[37] L.S. Andrade, M.C. De Moares, R.C. Rocha-Filho, O. Fatibello-Filho, Q.B. Cass, A multidimentional high performance liquid chromatography method using a boron-doped diamond electrode for the simultaneous determination of sulfomethoxazole and thrimethoprim in bovine milk, Anal. Chim. Acta 654 (2009) 127-132.

[38] A.F. Azevedo, F.A. Souza, J.T. Matsushima, M.R. Baldan, N.G. Ferreira, Detection of phenol at boron-doped monocrystalline diamond electrode, J.Electroanal.Chem. 658 (2011) 38-45.

[39] D. Khamis, E. Mahé, F. Dardoize, D. Devilliers, Peroxodisulfate generation on borondoped diamond microelectrodes array and detection by scanning electrochemical microscopy. J. Appl. Electrochem. 40 (2010) 1829-1838.

[40] K. Tsunozaki, Y. Einaga, T.N. Rao, A. Fujishima, Fabrication and electrochemical characterization of boron-doped diamond microdisc array electrodes. Chem. Lett. 5 (2002) 502-503.

[41] K.L. Soh, W.P. Kang, J.L. Davidson, S. Basu, Y.M. Wong, D.E. Cliffel, A.B. Bonds, G.M. Swain, Diamond derived microelectrodes array for electrochemical analysis, Diamond Relat. Mater. 13 (2004) 2009-2015.

[42] M. Pagels, C.E. Hall, N.S. Lawrence, A. Meredith, T.G.J. Jones, H.P. Godfried, C.S.J. Pickles, J. Wilman, C.E. Banks, R.G. Compton, L. Jiang, All diamond micro electrodes array device, Anal. Chem. 77 (2005) 3705-3708.

[43] C. Pietzka, A. Denisenko, L.A. Kibler, J. Scharpf, Y. Men, E. Kohn, Surface modification of single crystal boron-doped diamond electrodes for low back ground current, Diamond Relat. Mater. 18 (2009) 816-819.

[44] E. Vanhove, J. De Sanoit, J.C. Arnault, S. Saada, C. Mer, P. Mailley, P. Bergonzo, M. Nesladek, Stability of H terminated boron-doped diamond electrodes: An insight into the influence of the surface preparation, Phys. Stat. Sol. A 204 (2007) 2931-2939. 